\title{
Atividade Potencialmente Alelopática do Óleo Essencial de Ocimum americanum
}

\author{
Potentially Allelophatic Activity of the Essential Oil of Ocimum americanum
}

SOUZA FILHO, A.P.S. ${ }^{2}$, BAYMA, J.C. ${ }^{3}$, GUILHON, G.M.S.P. ${ }^{4}$ e ZOGHBI, M.G.B. ${ }^{5}$

\begin{abstract}
RESUMO - Os óleos essenciais são reconhecidos pelas suas diversificadas ações biológicas. A biodiversidade amazônica é rica em espécies de plantas produtoras de óleos essenciais. Neste trabalho, objetivou-se caracterizar a atividade potencialmente alelopática do óleo essencial de Ocimum americanum (estoraque) e determinar seus efeitos sobre a germinação de sementes e o desenvolvimento de duas espécies de plantas daninhas. O óleo essencial foi testado em concentrações variando de 100 a $2.000 \mathrm{mg} \mathrm{L}^{-1}$, considerando seus efeitos sobre a germinação de sementes $\left(25^{\circ} \mathrm{C}\right.$ de temperatura constante e fotoperiodo de 12 horas) e o desenvolvimento da radícula e do hipocótilo $\left(25^{\circ} \mathrm{C}\right.$ de temperatura constante e fotoperíodo de 24 horas) das plantas daninhas malícia (Mimosa pudica) e mata-pasto (Senna obtusifolia). Fatores relacionados a concentração, especificidade das plantas receptoras e parâmetros analisados foram decisivos para os efeitos obtidos. A tendência geral foi de relação positiva entre concentração e efeito inibitório. Malícia foi mais sensivel aos efeitos do que matapasto. Comparativamente, a germinação, seguida do desenvolvimento da radícula, foi afetada pelo óleo essencial em maior magnitude, ficando o desenvolvimento do hipocótilo como o de menor sensibilidade. Os efeitos observados podem ser atribuídos à presença, no óleo essencial, de monoterpenos, monoterpenos oxigenados, sesquiterpenos, alifáticos e fenilpropanoides, com destaque para os constituintes com atividade alelopática já comprovada, como o limoneno, a cânfora e o linalol.
\end{abstract}

Palavras-chave: alelopatia, constituinte químico, monoterpenos, sesquiterpenos, fenilpropanoides

\begin{abstract}
Essential oils are known for their several biological activities. The biodiversity of the Amazon region is rich in essential-oil producing plants. The aim of this work was to study the potentially allelopathic activity of the essential oil of Ocimum americanum and to determine its effects on seed germination and growth of two weed species. Solutions of the essential oil were tested at concentrations varying from 100 to $2,000 \mathrm{mg} \mathrm{L}^{-1}$, considering their effects on seed germination (at $25^{\circ} \mathrm{C}$ and a photoperiod of 12 hours) and radicle and hypocotyl growth (at $25^{\circ} \mathrm{C}$ and a photoperiod of 24 hours) of the weeds Mimosa pudica and Senna obtusifolia. Factors related to concentration, specificity of the receiving plants and the parameters analyzed were decisive for the effects obtained. Overall, there was a positive relation between concentration and inhibitory effect. M. pudica tended to be more sensitive to the effects than $\mathbf{S}$. obtusifolia. Seed germination was more affected by the essential oil, followed by radicle elongation and hypocotyl elongation. The observed effects can be attributed to the composition of the essential oil, that includes monoterpenes, sesquiterpenes, aliphatic compounds and phenylpropanoids. The compounds limonene, camphor and linalol, found in the essential oil, are known to have allelopathic activity.
\end{abstract}

Keywords: allelopathy, chemical composition, monoterpenes, sesquiterpenes, phenylpropanoids.

Recebido para publicação em 28.7.2008 e na forma revisada em 21.8.2009.

2 Engo-Agrọ ${ }^{\circ}$, Dr., Embrapa Amazônia Oriental, Trav. Dr. Enéas Pinheiro, S/N. 66.095-100 Belém-PA; ${ }^{3}$ Eng ${ }^{0}$ Químico, Dr., Universidade Federal do Pará - UFPA, Rua Augusto Corrêa, n. 1, 66075-900 Belém-PA; ${ }^{4}$ Engenheira Química, Dra., Universidade Federal do Pará, Rua Augusto Corrêa, n. 1, 66030-000 Belém-PA; ${ }^{5}$ Química, Dra., Museu Paraense Emílio Goeldi, Caixa Postal 369, 66045-000 Belém-PA.

Planta Daninha, Viçosa-MG, v. 27, n. 3, p. 499-505, 2009 


\section{INTRODUÇÃO}

Historicamente, os óleos essenciais têm desempenhado papel importante nas mais variadas atividades da humanidade. A utilização de espécies de plantas produtoras de óleos essenciais envolve desde a indústria de perfumes e de alimentos até a medicina popular (Sonowa \& König, 2001). Especificamente para as atividades agrícolas, informações referentes à possibilidade de utilização de óleos essenciais, de diferentes plantas, como alternativa viável para o controle de insetos estão disponiveis na literatura. Recentes investigações apontam que alguns óleos essenciais não apenas repelem insetos, como também apresentam ação inseticida e fumigante (Miyazawa et al., 1997; Ngoh et al., 1998; Isman, 2000). Outra possibilidade de uso de plantas produtoras de óleos essenciais, também na agricultura, é o controle de doenças fúngicas. Os trabalhos de Bastos \& Albuquerque (2004), Montes-Belmont \& Carvajal (1999) e Hoagland (1999), entre outros encontrados na literatura, apresentam informações relevantes sobre esse tópico.

Adicionalmente, os óleos essenciais revelam-se como potentes inibidores da germinação de sementes e do desenvolvimento de diferentes espécies de plantas (Romagni et al., 2000; Duke et al., 2002), levando à reflexão quanto à possibilidade e importância de seu emprego como bioerbicidas. Os trabalhos de Duke et al. (2000) e Kwak et al. (1999) enfatizam a importância desses constituintes das plantas como potentes agentes bioerbicidas.

A floresta amazônica brasileira, pela sua riqueza e diversidade biológica, pode oferecer a oportunidade para descobertas de inovadoras e eficientes moléculas com potencial para uso, em larga escala, na agricultura, tanto para o controle de pragas agrícolas de importância econômica, como também no controle de plantas daninhas. Especificamente em relação às plantas amazônicas produtoras de óleos essenciais, Maia et al. (2001) listaram 90 espécies de plantas nativas da Amazônia com essa característica, evidenciando todo o manancial à disposição para prospecção química.

Conquanto em número reduzido, estudos prospectivos visando identificar o potencial alelopático de óleos essenciais produzidos por espécies de plantas amazônicas foram desenvolvidos em passado recente, como são os casos dos trabalhos com Vouacapoua americana (espécie produtora de madeira de grande valor econômico e conhecida regionalmente pelo nome de acapu) (Paracambo, 2002), capimsalsar (Cymbopogon winteranius) (Dias \& Souza Filho, 2005) e capim-santo (C. citratus) (Souza Filho, 2006).

Ocimum americanum (Lamiaceae) é originária da Ásia e África e se naturalizou pela América tropical, onde é encontrada vegetando espontaneamente. É conhecida popularmente pelos nomes de alfavaca-devaqueiro e manjericão branco e anão. $\mathrm{Na}$ região amazônica, é conhecida pelo nome de estoraque. O gênero Ocimum inclui pelo menos 60 espécies e numerosa variedade. Ele representa importante fonte de óleo essencial usado na indústria de alimentos, perfumaria e cosméticos. Historicamente, algumas espécies de Ocimum são empregadas na medicina tradicional de países da África e Ásia (Khalid, 2006). Atividades biológicas de interesse agronômico, como bactericida, larvicida e repelente de insetos, são apresentadas nos trabalhos de Cimanga et al. (2002), Cavalcanti et al. (2004) e Seyoum et al. (2002).

Este trabalho teve por objetivos caracterizar a atividade potencialmente alelopática do óleo essencial de $O$. americanum e determinar seus efeitos sobre a germinação de sementes e o desenvolvimento de duas espécies de plantas daninhas de área de pastagens cultivadas.

\section{MATERIAL E MÉTODOS}

Coleta do material botânico e obtenção do óleo essencial: folhas e galhos de Ocimum americanum foram coletados no município de Belém, Estado do Pará. O material permaneceu em condições ambientais, até apresentar consistência quebradiça. A extração do óleo foi realizada por arraste, em extrator Cleveneger, por quatro horas seguidas. Após essa fase, quantidades de sulfato de sódio anidro foram adicionadas ao destilado, para secagem mais eficiente.

Processo de identificação dos constituintes químicos do óleo essencial: a identificação dos componentes do óleo essencial (\%) 
obedeceu às técnicas estabelecidas por Adams (2007), envolvendo espectro de massa, em sistema Shimadzu-QP2010 Plus, equipado com coluna capilar de sílica fundida Rtx-5MS (30 $\mathrm{m} \times 0,25 \mathrm{~mm} ; 0,25 \mathrm{~mm}$ ), operando nas seguintes condições: fluxo de coluna de

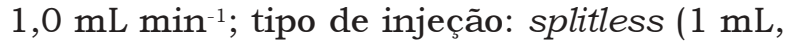
razão do split 2:1000), utilizando-se hélio como gás de arraste $\left(54,0 \mathrm{~mL} \mathrm{~min}^{-1}\right)$; temperatura programada do forno de $250{ }^{\circ} \mathrm{C}$; impacto eletrônico de $70 \mathrm{eV}$; temperatura da fonte dos ions de $200^{\circ} \mathrm{C}$; e temperatura de interface de $250{ }^{\circ} \mathrm{C}$. Os componentes foram identificados por comparação dos espectros de massa e índices de retenção (IR) com aqueles da biblioteca do sistema. Os dados quantitativos foram obtidos por integração eletrônica da área dos picos (TIC).

\section{Análise da atividade alelopática}

Bioensaio de germinação: a germinação foi monitorada em períodos de dez dias, com contagens diárias e eliminação das sementes germinadas. Foram consideradas sementes germinadas aquelas que apresentavam extensão radicular igual ou superior a $2,00 \mathrm{~mm}$ (Juntila, 1976; Duram \& Tortosa, 1985). Os bioensaios foram desenvolvidos em câmaras, com temperatura constante de $25^{\circ} \mathrm{C}$ e fotoperíodo de 12 horas. Cada placa de Petri de $9,0 \mathrm{~cm}$ de diâmetro, forrada com uma folha de papelfiltro qualitativo, recebeu 30 sementes previamente tratadas com ácido sulfúrico, para quebra de dormência, conforme estabelecido por Souza Filho et al. (1998).

Bioensaio de desenvolvimento de plantas: foi desenvolvido nas mesmas condições do bioensaio de germinação, diferindo apenas no fotoperiodo, que nesse caso foi de 24 horas. Cada placa de Petri de 9,0 cm de diâmetro, forrada com uma folha de papel-filtro qualitativo, recebeu três sementes pré-germinadas. No final do período de dez dias de crescimento, media-se o comprimento da radícula e do hipocótilo.

Outros procedimentos experimentais: cada placa de Petri recebeu 3,0 mL da solução-teste. Após a evaporação do solvente, adicionou-se mesmo volume de água destilada, mantendose, dessa forma, a concentração original. A solução-teste foi adicionada apenas uma vez, quando do início dos bioensaios, sendo adicionada, a partir de então, apenas água destilada, sempre que se fez necessário. O óleo essencial foi testado nas concentrações de 100, 200, 400, $600,800,1.000$ e $2.000 \mathrm{mg} \mathrm{L}^{-1}(\mathrm{v} / \mathrm{v})$, tendo como eluente o éter metílico.

Como plantas indicadoras dos efeitos, utilizaram-se as plantas daninhas Mimosa pudica (malícia) e Senna obtusifolia (matapasto). As sementes dessas espécies foram coletadas em áreas de pastagens cultivadas, no município de Castanhal, Estado do Pará. A escolha dessas duas espécies se deu pela importância que representam como plantas daninhas de áreas de pastagens cultivadas da região.

Delineamento experimental e análise estatistica: em todos os bioensaios, o delineamento experimental foi inteiramente casualizado, com quatro repetições, tendo como tratamento testemunha a água destilada, em modelo do tipo hierárquico com dois fatores. Os dados obtidos foram submetidos à análise de variância pelo teste $\mathrm{F}$, e as médias, comparadas pelo teste de Tukey (5\%). Nas análises utilizouse o programa computacional SAS (SAS, 1989).

\section{RESULTADOS E DISCUSSÃO}

Em estudos de avaliação da atividade fitotóxica envolvendo o uso de extratos brutos, cuidados especiais devem ser dispensados para o fator potencial osmótico dos extratos, até mesmo porque alelopatia e potencial osmótico apresentam efeitos aditivos, o que leva, em muitos casos, a superestimar os efeitos alelopáticos. Neste trabalho, as concentrações testadas variaram na faixa de $100 \mathrm{mg} \mathrm{L}^{-1}$ a $2.000 \mathrm{mg} \mathrm{L}^{-1}$; para essas condições, os efeitos osmóticos podem ser desconsiderados, conforme as indicações de Souza Filho \& Alves (2000).

A intensidade dos efeitos potencialmente alelopáticos variou em função da concentração e da planta receptora. A intensidade dos efeitos esteve positivamente associada à concentração, com valores mínimos e máximos verificados nos limites inferior e superior, respectivamente; nas concentrações mais baixas esses acréscimos não corresponderam a diferenças $(p>0,05)$ estatísticas. As inibições efetivadas sobre a germinação das sementes 
de malícia variaram entre 9,0 e $89,0 \%$ e, sobre mata-pasto, de 10,0 a $78,0 \%$, respectivamente para as concentrações de 100 e $2.000 \mathrm{mg} \mathrm{L}^{-1}$ (Tabela 1).

A tendência geral observada foi de a germinação das sementes de malícia ser inibida em magnitude superior à daquelas de mata-pasto, com exceção dos efeitos promovidos nas concentrações de 100 e $200 \mathrm{mg} \mathrm{L}^{-1}$, quando não foram verificadas diferenças estatísticas $(p>0,05)$. Para malícia, inibições da germinação das sementes acima de 50\% foram obtidas apenas em concentração igual ou superior a $800 \mathrm{mg} \mathrm{L}^{-1}$, enquanto para matapasto esse efeito foi observado para concentração igual ou superior a $1.000 \mathrm{mg} \mathrm{L}^{-1}$. Esses resultados apontam a espécie malícia como de maior sensibilidade aos efeitos alelopáticos do óleo essencial de $O$. americanum.

As inibições promovidas sobre o desenvolvimento da radícula (Tabela 2) foram similares às verificadas sobre a germinação das sementes, tanto em termos de intensidade como de sensibilidade das duas espécies aos efeitos do óleo essencial. À semelhança do observado em relação aos efeitos sobre a germinação, malícia foi novamente a espécie mais sensivel, embora diferenças estatísticas $(p<0,05)$ entre as duas espécies não tenham sido observadas a $100 \mathrm{mg} \mathrm{L}^{-1}$. Entretanto, inibições acima de $50 \%$ foram obtidas na mesma concentração (800 $\mathrm{mg} \mathrm{L}^{-1}$ ), nas duas espécies.

Os efeitos sobre o desenvolvimento do hipocótilo (Tabela 3) seguiram as mesmas tendências dos observados sobre a germinação

Tabela 1 - Efeitos potencialmente alelopáticos do óleo essencial de estoraque sobre a germinação de sementes de plantas daninhas. Dados expressos em percentual de inibição em relação ao tratamento testemunha - água destilada

\begin{tabular}{|c|c|c|}
\hline Concentração & \multicolumn{2}{|c|}{ Planta daninha } \\
\hline$\left(\mathrm{mg} \mathrm{L}^{-1}\right)$ & Malícia & Mata-pasto \\
\hline 100 & $9,0 \mathrm{Ga}$ & $10,0 \mathrm{Fa}$ \\
\hline 200 & $14,0 \mathrm{Fa}$ & $12,0 \mathrm{Fa}$ \\
\hline 400 & $27,0 \mathrm{Ea}$ & $22,0 \mathrm{~Eb}$ \\
\hline 600 & $35,0 \mathrm{Da}$ & $30,0 \mathrm{Db}$ \\
\hline 800 & $53,0 \mathrm{Ca}$ & $43,0 \mathrm{Cb}$ \\
\hline 1.000 & $69,0 \mathrm{Ba}$ & $59,0 \mathrm{Bb}$ \\
\hline 2.000 & $89,0 \mathrm{Aa}$ & $78,0 \mathrm{Ab}$ \\
\hline
\end{tabular}

Médias seguidas de letras iguais, maiúsculas na coluna e minúsculas na linha, não diferem pelo teste de Tukey $(5 \%)$.
Tabela 2 - Efeitos potencialmente alelopáticos do óleo essencial de estoraque sobre o desenvolvimento da radícula de plantas daninhas. Dados expressos em percentual de inibição em relação ao tratamento testemunha - água destilada

\begin{tabular}{|c|c|c|}
\hline Concentração & \multicolumn{2}{|c|}{ Planta daninha } \\
\hline$\left(\mathrm{mg} \mathrm{L}^{-1}\right)$ & Malícia & Mata-pasto \\
\hline 100 & $5,0 \mathrm{Ga}$ & $4,0 \mathrm{Fa}$ \\
\hline 200 & $12,0 \mathrm{Fa}$ & $5,0 \mathrm{Fb}$ \\
\hline 400 & $27,0 \mathrm{Ea}$ & $19,0 \mathrm{~Eb}$ \\
\hline 600 & $47,0 \mathrm{Da}$ & $40,0 \mathrm{Db}$ \\
\hline 800 & $59,0 \mathrm{Ca}$ & $51,0 \mathrm{Cb}$ \\
\hline 1.000 & $72,0 \mathrm{Ba}$ & $64,0 \mathrm{Bb}$ \\
\hline 2.000 & $86,0 \mathrm{Aa}$ & $78,0 \mathrm{Ab}$ \\
\hline
\end{tabular}

Médias seguidas de letras iguais, maiúsculas na coluna e minúsculas na linha, não diferem pelo teste de Tukey (5\%).

Tabela 3 - Efeitos potencialmente alelopáticos do óleo essencial de estoraque sobre o desenvolvimento do hipocótilo de plantas daninhas. Dados expressos em percentual de inibição em relação ao tratamento testemunha - água destilada

\begin{tabular}{|c|c|c|}
\hline Concentração & \multicolumn{2}{|c|}{ Planta daninha } \\
\hline$\left(\mathrm{mg} \mathrm{L}^{-1}\right)$ & Malícia & Mata-pasto \\
\hline 100 & $5,0 \mathrm{Fa}$ & $3,0 \mathrm{Fa}$ \\
\hline 200 & $7,0 \mathrm{Fa}$ & $5,0 \mathrm{Fa}$ \\
\hline 400 & $16,0 \mathrm{Ea}$ & $15,0 \mathrm{Ea}$ \\
\hline 600 & $30,0 \mathrm{Da}$ & $21,0 \mathrm{Db}$ \\
\hline 800 & $37,0 \mathrm{Ca}$ & $29,0 \mathrm{Cb}$ \\
\hline 1.000 & $48,0 \mathrm{Ba}$ & $36,0 \mathrm{Bb}$ \\
\hline 2.000 & $53,0 \mathrm{Aa}$ & $42,0 \mathrm{Ab}$ \\
\hline
\end{tabular}

Médias seguidas de letras iguais, maiúsculas na coluna e minúsculas na linha, não diferem pelo teste de Tukey (5\%).

e o desenvolvimento da radícula, com diferença na intensidade de inibição, que foi menor. Repetindo os resultados anteriores, malícia foi novamente mais sensivel aos efeitos do óleo do que mata-pasto; diferenças estatísticas significativas $(p<0,05)$ só foram observadas entre essas duas espécies em concentração igual ou superior a $600 \mathrm{mg} \mathrm{L}^{-1}$. Inibição do hipocótilo acima de $50 \%$ foi observada apenas na concentração de $2.000 \mathrm{mg} \mathrm{L}^{-1}$ e somente para malícia. O conjunto dessas informações aponta o desenvolvimento do hipocótilo como o menos sensivel aos efeitos alelopáticos, e a germinação das sementes, como a mais sensivel.

Os resultados encontrados neste trabalho são similares àqueles disponiveis na literatura, com pequenas variações decorrentes de fatores como concentrações e espécies 
receptoras diferentes. Dudai et al. (1999), por exemplo, estudaram os óleos essenciais de três espécies de plantas aromáticas com propriedades alelopáticas. A germinação de várias espécies de plantas, incluindo o trigo, foi fortemente inibida quando os óleos foram aplicados em concentrações de 20-80 ppm; quanto mais altas as concentrações, maiores foram os efeitos inibitórios. Vilhena (2006) comparou a atividade potencialmente alelopática de duas espécies de Cyperus e atribuiu as variações nas intensidades dos efeitos inibitórios às diferenças verificadas na composição química dos óleos.

A atividade biológica de um dado aleloquímico depende tanto da concentração como do limite da resposta da espécie afetada. O limite de inibição para um dado químico não é constante, porém está intimamente relacionado à sensibilidade da espécie receptora, aos processos metabólicos da planta e às condições ambientais. No presente trabalho, essas tendências foram observadas tanto em relação ao fator concentração, cujos efeitos inibitórios estiveram positivamente associados à concentração do óleo, como em relação às espécies receptoras; malícia apresentou limite de resposta inferior àquele evidenciado por matapasto, indicando a espécie malícia como de maior sensibilidade. Esses pontos foram detectados quando se analisaram os efeitos tanto sobre a germinação das sementes (Tabela 1) quanto sobre o desenvolvimento da radícula (Tabela 2) e do hipocótilo (Tabela 3) das duas espécies de plantas receptoras. Essas tendências nem sempre foram acompanhadas de diferenças estatísticas ( $p>0,05)$, tendo sido mais marcantes para o fator germinação de sementes e menos para desenvolvimento do hipocótilo.

De acordo com An et al. (1993), considerase que um dado aleloquímico possui dois atributos: inibitório e estimulatório. Rice (1984) menciona que, quando em baixa concentração, os efeitos alelopáticos podem não ser inibitórios para dada espécie receptora, podendo ocorrer efeitos estimulatórios em determinados casos. Os resultados obtidos neste trabalho mostram que, mesmo em concentração tão baixa quanto $100 \mathrm{mg} \mathrm{L}^{-1}$, os efeitos foram sempre inibitórios para as duas espécies receptoras, indicando que provavelmente somente em concentrações inferiores efeitos estimulatórios podem ser esperados. A diferença na sensibilidade evidenciada pelas duas espécies aos efeitos dos óleos essenciais pode contribuir para maior ou menor extensão desses efeitos.

Os efeitos do óleo essencial sobre a germinação de sementes e o desenvolvimento de plantas são frequentemente explicados em termos individuais de alguns dos principais constituintes. Entretanto, o óleo essencial é uma mistura de diferentes componentes em proporções variadas, e é frequentemente desconhecido se e como esses constituintes interagem entre si e promovem seus efeitos sobre outros organismos. Paralelamente, há considerável variação na composição dos constituintes do óleo essencial de certas espécies de plantas; essa variação pode ocorrer tanto em função da sazonalidade como da diferença entre indivíduos de diferentes populações e de mesma população (Kokkini \& Vokou, 1989; Tarayre et al., 1995). Langenhein (1994) ressalta a importância dos constituintes do óleo essencial das plantas e relaciona essa característica à maior ou menor atividade alelopática. A exemplo desses aspectos, Komai et al. (1991) analisaram diferentes espécies de Cyperus e indicaram que os óleos essenciais daqueles que apresentavam maiores indices de inibição alelopática eram constituídos principalmente por sesquiterpenos que continham o grupo cetona ou hidroxila; os óleos constituídos de grupo acetato ou somente de hidrocarboneto apresentaram menor atividade alelopática. Weidenhamer et al. (1993) ressaltam o poder fitotóxico dos monoterpenos e monoterpenos oxigenados como agentes alelopáticos.

Entre os constituintes químicos do óleo essencial da espécie $O$. americanum, foram identificados monoterpenos, monoterpenos oxigenados, sesquiterpenos, compostos alifáticos e fenilpropanoides. Os constituintes em maior proporção percentual foram o limoneno (24,0\%), linalol (10,6\%), (E)-cinamato de metila $(17,0 \%)$ e carvona $(8,6 \%)$ (Tabela 4). Especificamente entre aqueles constituintes químicos de óleo essencial com atividade alelopática já comprovada e que podem estar envolvidos nos efeitos observados neste trabalho, isoladamente ou em associação com outros componentes, 
Tabela 4 - Composição química do óleo essencial (\%) de estoraque

\begin{tabular}{|l|c|c|}
\hline \multicolumn{1}{|c|}{ Componente (\%) CG/EM } & IR & Valor (\%) \\
\hline$\alpha$-tujeno & 931 & 0,4 \\
\hline$\alpha$ - pineno & 938 & 3,4 \\
\hline 1-octen-3-ol & 980 & 0,5 \\
\hline Mirceno & 994 & 1,4 \\
\hline Limoneno & 1.032 & 24,0 \\
\hline$\gamma$ - terpineno & 1.061 & 0,3 \\
\hline Fenchona & 1.092 & 2,7 \\
\hline Linalol & 1.102 & 10,6 \\
\hline Acetato de 1-octen-3-il & 1.113 & 1,0 \\
\hline Cânfora & 1.148 & 0,1 \\
\hline 4-terpineol & 1.180 & 0,3 \\
\hline$\alpha$ - terpineol & 1.194 & 0,2 \\
\hline Trans-carveol & 1.222 & 0,4 \\
\hline Cis-carveol & 1.233 & 0,5 \\
\hline Carvona & 1.248 & 8,6 \\
\hline Acetato de bornila & 1.299 & traços \\
\hline Z)-cinamato de metila & 1.309 & 5,5 \\
\hline Acetato de mirtenila & 1.329 & traços \\
\hline Acetato de transcarvila & 1.340 & traços \\
\hline$\alpha$ - copaceno & 1.379 & 0,1 \\
\hline (E)-cinamato de metila & 1.389 & 17,0 \\
\hline$\beta$ - elemeno & 1.396 & 0,7 \\
\hline$\beta$ - cariofileno & 1.424 & 5,7 \\
\hline Trans- $\alpha$ - bergamoteno & 1.439 & 2,4 \\
\hline Z)- $\beta$ - farneseno & 1.446 & traços \\
\hline (E)- $\beta$ - farneseno & 1.454 & 2,0 \\
\hline$\beta$ - selineno & 1.500 & 2,7 \\
\hline$\beta$ - bisaboleno & 1.511 & 0,5 \\
\hline$\delta$ - cadineno & 1.526 & 0,2 \\
\hline
\end{tabular}

IR = índice de retenção.

estão o limoneno, a cânfora e o linalol (Fischer, 1991; Vokou et al., 2003). Entre esses três constituintes já catalogados como agentes alelopáticos, limoneno e linalol merecem destaque, até pela alta proporção com que participam no total do óleo essencial de O. americanum.

\section{LITERATURA CITADA}

ADAMS, R. P. Identification of essential oil components by gas chromatography/mass spectrometry. London: Allured Publication, 2007. 804 p.

AN, M.; JOHNSON, I. R.; LOVETTE, J. V. Mathematical modeling of allelopathy: biological response to allelochemical and its interpretation. J. Chem. Ecol., v. 19, n. 10, p. 23792389,1993

BASTOS, C. N.; ALBUGUERQUE, P. S. B. Efeitos do óleo de Piper aduncum no controle e pós-colheita de Colletrotricum musae em banana. Fitopatol. Bras., v. 29, n. 5, p. 555-557, 2004.
CAVALCANTI, E. S. B. et al. Larvicidal activity of essential oils from Brazilian plants against Aedes aegypti L. Mem. Inst. Oswaldo Cruz, v. 99, n. 5, p. 354-363, 2004.

CIMANGA, K. et al. Correlation between chemical composition and antibacterial acticity of essential oils of some aromatic medicinal plants. J. Enthemopharmacology, v. 79, n. 2, p. 213-220, 2002.

DIAS, A. P. C.; SOUZA FILHO, A. P. S. Atividade potencialmente alelopática em extratos hidroalcoólicos de Cymbopogon sp. (Poaceae). R. Ci. Agrária, v. 44, n. 1, p. $37-48,2005$.

DUDAI, N. et al. Essential oil as allelochemicals and their potential use as bioerbicidas. J. Chem. Ecol., v. 25, n. 5, p. 1079-1089, 1999

DUKE, S. O. et al. Chemical from nature for weed management. Weed Sci., v. 50, n. 2, p. 138-151, 2002.

DUKE, S. O.; ROMAGNI, J. G.; DAYAN, F. E. Natural products as source from new mechanisms of herbicidal action. Crop Prod., v. 19, n. 8/10, p. 583-589, 2000.

DURAM, R. D.; TORTOSA, M. F. The effect of mechanical and chemical scarification on germination of charlock (Snapsis arvensis L.) seeds. Seed Sci. Technol., v. 13, n. 1, p. 155-163, 1985.

FISCHER, N. H. Plant terpenoids as allelopathy agents. In: HARBONE, J. B.; TOMES-BARBERAN, F. A. (Eds)

Ecological chemistry and biochemistry of plant terpenoids. Oxford: Clarendon, 1991. p. 377-399.

HOAGLAND, R. E. Allelopathic interaction of plant and pathogens. In: MACIAS, F. A. et al. (Eds.). Recent advances in allelophaty. Cádiz: International Allelopathy Society, 1999. p. 423-450.

ISMAN, M. B. Plant essential oil for pest and disease management. Crop Protec., v. 19, n. 8/10, p. 603-608, 2000

JUNTILA, O. Seed and embryo germination in S. vulgaris and $S$. reflexa as affected by temperature during seed development. Phisol. Plant., v. 29, n. 2, p. 264-268, 1976

KOKKINI, S.; VOKOU, D. Mentha spicata (Lamiaceae) chemotypes growing wild in Greece. Econ. Bot., v. 43, n. 2, p. 192-202, 1989.

KHALID, K. H. A. Influence of water stress on growth, essential oil, and chemical composition of herbs (Ocimum sp.). Inst. Agrophysics, v. 20, n. 4, p. 289-296, 2006.

KOMAI, K.; TANG, C. S.; NISHIMOTO, R. K. Chemotypes of Cyperus rotundus in Pacific Rim and inhibitory of their essential oils. J. Chem. Ecol., v. 17, n. 1, p. 1-11, 1991. 
KWAK, S. H. et al. Allelopathy effects of Chamaecyparis obtuse in Korea. In: MACIAS, F.A. et al. (Eds.). Recent advances in allelophaty. Cádiz: International Allelopathy Society, 1999. p. 269-286.

LANGENHEIN, J. K. Higher plant terpenoids: a phytotocentric overview of their ecological roles. J. chem. Ecol., v. 20, n. 6, p. 1223-1282, 1994.

MAIA, J. G. S.; ZOGHBI, M. G. B.; ANDRADE, E. H. A. Plantas aromáticas da Amazônia e seus óleos essenciais. Belém: Museu Paraense Emílio Goeldi, 2001. 173 p.

MIYAZAWA, M.; WATANABE, H.; KAMEOKA, H. Inhibition of acetylcholinesterase activity by monoterpenods with a $p$-methane skeleton. J. Agric. Food Chem., v. 45, n. 3, p. 677-679, 1997.

MONTES-BELMONT, R.; CARVAJAL, M. Aspergillus flavus control in maize with plant essential oil. In: MACIAS, F. A. et al. (Eds.). Recent advances in allelophaty. Cádiz: International Allelopathy Society, 1999. p. 463-470.

$\mathrm{NGOH}, \mathrm{S}$. P. et al. Insecticidal and repellent properties of nine volatile constituents of essential oils against the American cockroach (Periplaneta Americana L.). Pestic. Sci., v. 54, n. 3, p. 261-268, 1998.

PARACAMPO, N. E. N. Estudo químico e avaliação da atividade fitotóxica e fungitóxica de extratos de Vouacapoua cf. americana. 2002. 63 f. Dissertação (Mestrado em Química) - Universidade Federal do Pará, Belém, 2002.

RICE, E. L. Allelopathy. New York: Academic Press, 1984. $422 \mathrm{p}$.

ROMAGNI, J. G.; DUKE, S. O.; DAYAN, F. E. Inhibition of plant aspergine shynthetase by monoterpene cineol. Plant Physiol., v. 123, n. 2, p. 725-732, 2000.
SAS Institute. Statistical Analyses System. User's guide. Version 6.4. ed. Cary: 1989. 846 p.

SEYOUM, A. et al. Repellency of live potted plants against Anopheles gambiae from human baits in semi-field experimental huts. Am. J. Med. Hyg., v. 67, n. 2, p. 191-195, 2002.

SONOWA, M. M.; KÖNIG, W. A. Constituents of the essential oil of Cyperus alopecuroides. Phytochemistry, v. 56, n. 4 , p. $321-325,2001$.

SOUZA FILHO, A. P. S. Alelopatia e as plantas. Belém: Embrapa, 2006. 159 p.

SOUZA FILHO, A. P. S.; ALVES, S. M. Potencial alelopático de plantas de acapu (Vouacapoua americana): efeitos sobre plantas daninhas de pastagens. Planta Daninha, v. 18, n. 3, p. $435-441,2000$.

SOUZA FILHO, A. P. S.; DUTRA, S.; SILVA, M. A. M. M. Métodos de superação da dormência de sementes de plantas daninhas de pastagens cultivadas da Amazônia. Planta Daninha, v. 16, n. 1, p. 2-11, 1998

TARAYRE, M. et al. Intraspecific variation in the inhibition effects of Thymas vulgaris (labiatae) monoterpenes on seed germination. Oecologia, v. 101, n. 1, p. 110-118, 1995.

VILHENA, K. S. S. Estudo químico e atividade alelopática dos extratos brutos e do óleo essencial dos rizomas de Cyperus articulatum L. e Cyperus giganteus Vahl. (Cyperaceae). 2006. 130 f. Dissertação (Mestrado em Química)-Universidade Federal do Pará, Belém, 2006.

VOKOU, D. et al. Effects of monoterpenoids, acting alone or in pairs, on seed germination and subsequent seedling growth. J. Chem. Ecol., v. 29, n. 10, p. 2281-2301, 2003.

WEIDENHAMER, J. D. et al. Just how insoluble are monoterpenes? J. Chem. Ecol., v. 19, n. 8, p. 1799-1807, 1993. 